\title{
Cervical spine injuries requiring surgery in a Level I trauma centre in a major German city
}

\author{
Roslind Karolina Hackenberg ${ }^{1,2}\left(\right.$ D $\cdot$ Paul Stoll ${ }^{1} \cdot$ Kristian Welle $^{1} \cdot$ Jasmin Scorzin $^{3} \cdot$ Martin Gathen $^{1}$. \\ Charlotte Rommelspacher ${ }^{1} \cdot$ Koroush Kabir $^{1}$
}

Received: 9 July 2021 / Accepted: 10 October 2021 / Published online: 26 October 2021

(c) The Author(s) 2021, corrected publication 2022

\begin{abstract}
Background Cervical spine injuries (CSI) are rare in trauma patients, at about 9.2-16.5/100,000 inhabitants in Scandinavia and Canada, and the annual incidence of CSI surgeries in Norway is around 3.0/100,000 inhabitants. However, despite their rarity, the incidence of CSI has increased, thereby assuming an increasing need for surgery. Outside of Scandinavia, no data about the incidence of CSI and subsequent surgeries exist. Therefore, this study aimed to analyse CSI epidemiology and surgery in a German city with a Level I trauma centre both to understand the injury and improve needs-based planning.

Methods This retrospective, monocentre study included all patients who presented with CSI from 2012-2017 at a university hospital with a Level I trauma centre in a major German city and had permanent residency within the city. Based on the assumption that the patients represented all CSI injuries in the city, as they were treated at the only available Level I trauma centre, the annual incidence of surgeries and neurologic deficits due to CSI were calculated.

Results A total of 465 patients with 609 CSI were identified. Of these patients, 61 both received surgery and resided in the city (mean age, $68.1 \pm 18.3$ years; 26 female, 35 male). The incidence of CSI surgeries was calculated as 3.24/100,000 person years (1.75/100,000 in the upper and 1.54/100,000 in the subaxial cervical spine). Neurologic deficits occurred in $0.64 / 100,000$ person years. The incidence of both surgeries and neurologic deficits showed no significant changes over the 6-year study period.

Conclusions Compared to Scandinavia, an increasing annual incidence for CSI surgeries and neurologic deficits were found. For long-term demand planning with adaptability to demographic changes, cross-regional studies including long-term follow-up are necessary.
\end{abstract}

Keywords Cervical spine $\cdot$ Incidence $\cdot$ Injury $\cdot$ Surgery $\cdot$ Neurology

\section{Abbreviation}

CSI Cervical spine injuries

This article is part of the Topical Collection on Spine trauma

Roslind Karolina Hackenberg

Roslind.hackenberg@ukbonn.de

1 Department of Orthopedic and Trauma Surgery, University Hospital Bonn, Venusberg-Campus 1, 53127 Bonn, Germany

2 Department of Hand, Plastic and Reconstructive Surgery, Burn Center, BG Trauma Center Ludwigshafen, University Hospital Heidelberg, Ludwigshafen, Germany

3 Department of Neurosurgery, University Hospital Bonn, Bonn, Germany

\section{Introduction}

Cervical spine injuries (CSI) are a rare entity among trauma and polytrauma patients [4]. In Scandinavia, the annual incidence of cervical spine fractures was found to be 9.2-15/100,000 inhabitants [2, 6]. Additionally, soft tissue injuries of the cervical spine were found in 1.5-8/100,000 inhabitants each year [2, 6]. Furthermore, the overall incidence of CSI was estimated to be 16.5-17.2/100,000 inhabitants per year in Norway and Sweden $[2,6]$ and 12/100,000 inhabitants per year in Canada $[6,8]$. The annual incidence of CSI hospital admissions in China was found to be $65 / 100,000$ patients [16]. However, despite their rarity in relation to the general population and all patients, the incidence of traumatic CSI has significantly increased over the last few decades $[9,13]$. In $2005,4.1 \%$ of all trauma patients in the USA suffered from CSI; this rate significantly 
increased to 5.4\% in $2013(p<0.001)$ [13]. Another study showed that $6.7 \%$ of all polytraumatized patients in the USA present with CSI [4].

The age distribution and gender ratio of CSI have also changed. In 1992, the mean age of patients with CSI was 20-29 years in the UK [15]. In the USA, the mean age had increased to 59 years in 2013 [13], and the incidence of CSI in Norway has significantly increased with increasing age [6, 7]. Furthermore, although the gender ratio of CSI favours men, at 1.5-4.3:1 [2, 4, 10, 13, 16], the amount of women presenting with CSI has significantly increased, specifically with increasing age $[2,9]$.

Of all CSI, $18-33.5 \%$ require surgery $[6,7,13]$. In Norway, the annual incidence of CSI surgeries was estimated to be 3.0-3.1/100,000 inhabitants $[6,7]$. However, due to the increasing incidence and changing demographics of CSI, the need for CSI surgeries will likely increase as well. Outside of Scandinavia, though, no data exist concerning CSI incidence, specifically their need for surgery and the rate of coexisting neurologic deficits. This knowledge is not only important for understanding the injury but also essential for needs-based planning. Therefore, this study aimed to analyse CSI epidemiology and need for surgeries in a major German city with one Level I trauma centre.

\section{Methods and materials}

This retrospective, monocentre study included all patients who presented with and received surgical treatment for traumatic CSI at the Level I trauma centre between January 2012 and December 2017. The centre is in the only maximum medical care hospital in the city that has departments of orthopaedic and trauma surgery and neurosurgery. The inclusion criteria were as follows: one or more injuries in the upper and/or subaxial cervical spine, which were assured via $\mathrm{X}$-ray, computed tomography, or magnetic resonance imaging; a recent trauma; and permanent residency in the city of Bonn. The upper cervical spine was defined as the levels $\mathrm{C} 0-\mathrm{C} 2$ and the subaxial cervical spine was defined as the levels C3 to C7. Patients with residence outside of the city and without an osseous or ligamentous CSI, adequate trauma history, or surgical treatment were excluded. Adequate trauma was defined as follows: (1) a traffic accident with a change of velocity of at least $30 \mathrm{~km} / \mathrm{h}$ that included motor vehicles, motorcycles, bicycles, scooters, and/or pedestrians; (2) a fall, including falls from a height of at least $1 \mathrm{~m}$ and staircase falls; and (3) low-energy trauma with a direct impact to the head, including falls from a height of less than $1 \mathrm{~m}$ and sports accidents. Patients with an isolated spinal cord injury but without an osseous or ligamentous injury, pathologic fractures, or osteoporotic insufficiency fractures were also excluded.
The regional trauma network included one university hospital, which was a maximum medical care hospital with a Level I trauma centre. The network also included four hospitals with a Level III trauma centre and four hospitals with a Level IV trauma centre. As per regulations within and between the regional trauma networks, patients were transferred to the closest available and most appropriate trauma centre. Besides the hospital included in the present study, the nearest maximum medical care hospitals with Level I trauma centres were at a distance of $30 \mathrm{~km}, 32 \mathrm{~km}, 54 \mathrm{~km}$, and $80 \mathrm{~km}$. Due to potential overlap of the rural catchment area, only patients with residency in the city of Bonn were selected and included.

Age, gender, localization of the injury, neurologic deficits, method of admission (i.e., immediate presentation through self-initiative or emergency medical service or transfer from a peripheral hospital), length of hospital stay in our institution, and treatment were documented from the patient records. Based on the assumption that all patients with severe CSI, such as those with neurologic deficits or an indication for surgery, presented and were treated at the only available centre in the city, the annual incidence of traumatic CSI with neurologic deficits and those necessitating surgery was calculated using the number of inhabitants of the city of Bonn. Descriptive statistical analysis was performed using SPSS Statistics, Version 25.0 (IBM, Armonk, NY, USA). The level of significance was defined at $p<0.05$.

The study was approved by the local ethics committee of the University Hospital Bonn (local review board number 250/18) and performed in accordance with the ethical standards of the institutional and national research committee and the 1964 Helsinki declaration and its later amendments.

\section{Results}

\section{Study population}

Between January 2012 and December 2017, a total of 465 patients with 609 CSI were treated at the university hospital, 130 of whom had permanent residence within the city. Of the 130 patients with a mean age of $67.5 \pm 20.4$ years, 61 received surgery (46.9\%), while 58 received conservative treatment $(44.6 \%)$ with a cervical collar for an average of 6 weeks, and 11 did not need a specific treatment $(8.5 \%)$, because their injury had no risk for instability or non-union. The incidence of CSI surgeries was calculated by means of the 61 patients who received surgical treatment.

Table 1 displays the patients' characteristics. The mean age was $68.1 \pm 18.3$ years (range, $20-90$ years). Of the patients, 26 were female $(42.6 \%)$, and 35 were male 
Table 1 Patient characteristics in CSI surgery

\begin{tabular}{llll}
\hline Year & & Total & $\emptyset /$ year \\
\hline Number of patients $[n]$ & & 61 & 10.17 \\
Age $[y ;$ SD] & & \multicolumn{2}{c}{$68.07 \pm 18.33$ (min. } \\
& Male & $20 ;$ max. 92) & \\
Gender $[n]$ & Female & 35 & 5.83 \\
& Immediate presentation & 26 & 4.33 \\
Method of admission $[n]$ & Transfer & 34 & 5.67 \\
& & 27 & 4.50 \\
Length of hospital stay $[d ;$ SD] & & $22.97 \pm 20.25$ (min. \\
& Upper cervical spine & $5 ;$ max. 88) & \\
Localisation $[n]$ & Subaxial cervical spine & 32 & 5.33 \\
& Combined & 28 & 4.67 \\
Neurology $[n]$ & None & 1 & 0.17 \\
& Radiculopathy & 50 & 8.33 \\
& Incomplete spinal cord injury & 3 & 0.67 \\
& Complete spinal cord injury & 4 & 0.50 \\
& & 4 & 0.67 \\
\hline
\end{tabular}

\section{Incidence}

Both patient age and gender distribution showed no significant changes during the 6-year study period $(p>0.05)$. However, the elderly, especially patients with an age of $>60$ years, suffered more often from CSI and had a higher risk for CSI necessitating surgery with patients between 61 and 80 years representing the group at highest risk (Fig. 1). Of the patients, 34 (55.7\%) had an immediate presentation, either by self-initiative or via emergency medical services; 27 (44.3\%) were transferred from a regional hospital for treatment. The mean length of hospital stay was $23.0 \pm 20.3$ days and showed no significant changes during the six-year study period $(p>0.05)$.

On average, 10.2 patients in the city of Bonn suffered from CSI that were treated surgically each year. With an average number of 314,000 citizens, this resulted in an incidence of $3.24 / 100,000$ person years for traumatic CSI receiving surgery. No significant changes in the incidence of CSI surgeries were observed during the study period $(p>0.05)$.

\section{Neurology}

Of the 61 patients, 11 had neurologic deficits because of their CSI; four suffered from a radiculopathy with emphasis on the upper extremities, three suffered from incomplete spinal cord injury, and four suffered
Fig. 1 Incidence of surgeries in cervical spine injuries according to age per 100.000 person years

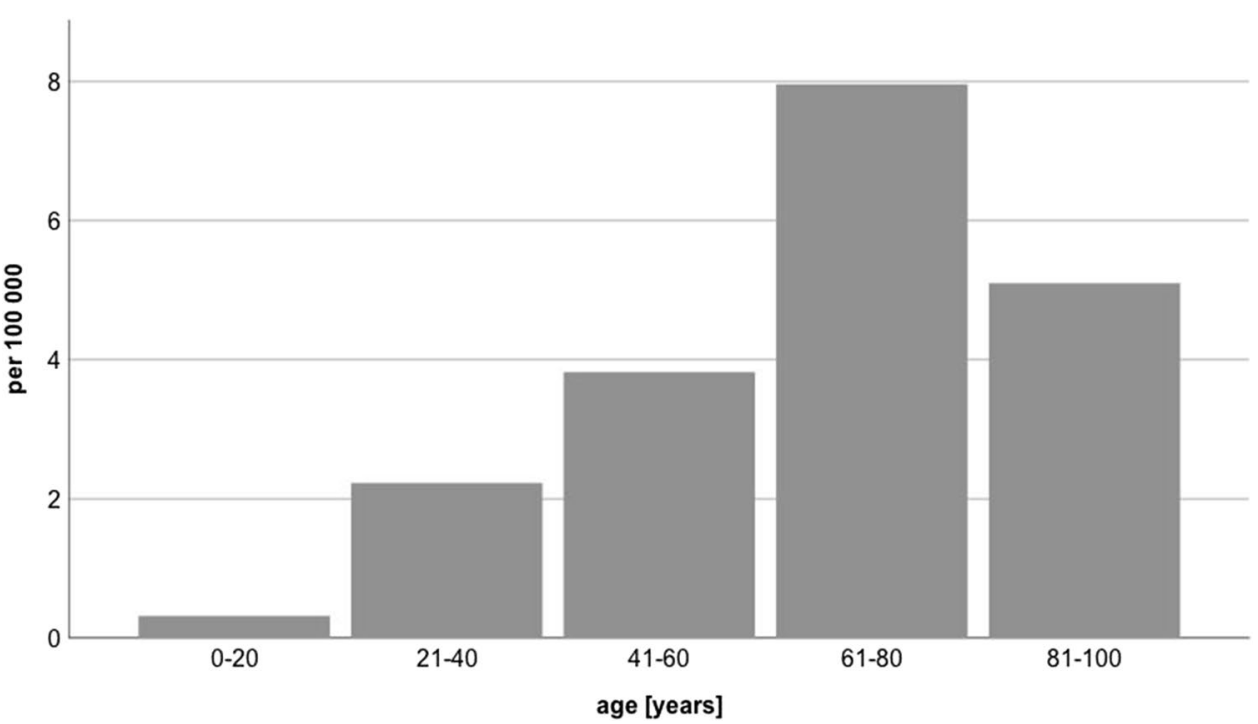


from complete spinal cord injury. On average, two patients suffered from neurologic deficits accompanying their CSI each year. Therefore, an incidence of $0.64 / 100,000$ person years for neurologic deficits due to CSI was determined (Table 2). Furthermore, complete spinal cord injury due to CSI was found in $0.21 / 100,000$ person years. No significant increase or decrease was determined in the incidence of neurologic disabilities accompanying CSI throughout the study period.

Of the 130 patients with CSI and a residency in Bonn being treated at the Level I trauma centre, 12 patients suffered from spinal cord injury with neurologic deficits. Based on the assumption that all patients with CSI and neurologic deficits in Bonn presented at our institution, the rate for neurologic disabilities in CSI is calculated to be $<9.2 \%$.

\section{Localization of injury}

Of the surgically treated CSI, 32 were located in the upper cervical spine, while 28 were located in the subaxial cervical spine. One patient suffered from a combined injury in the upper and subaxial cervical spine that needed surgery. Therefore, the average annual rate was 5.5 injuries in the upper cervical spine and 4.8 injuries in the subaxial cervical spine that were treated with surgery, including combined injuries. Combined injuries receiving surgery averaged 0.17 patients/year. For surgically treated injuries in the upper cervical spine, an incidence of $1.8 / 100,000$ person years was found, while the incidence for surgically treated injuries in the subaxial cervical spine was $1.5 / 100,000$ person years (Table 2). The incidence of combined injuries in the upper and subaxial cervical spine was $0.054 / 100,000$ person years. On average, $14 \%$ more surgeries were performed on account of injuries in the upper cervical spine than the subaxial cervical spine. There was no significant difference in the incidence concerning the localization of injury during the observation period.

\section{Discussion}

The present study was the first to assess the incidence of CSI surgeries as well as the incidence of neurologic deficits due to CSI, for a major German city. The annual incidence of CSI is 17.2/100,000 inhabitants in Sweden [2], 12/100,000 in Canada [6, 8], and 11.8-16.5/100,000 for Norway [6, 7]. Unlike the present study, studies of Scandinavian and Canadian patients also included those with a spinal cord injury without additional osseous or ligamentous injuries of the cervical spine, whereas these patients were excluded from the present study.

Both the mean age of all patients who presented with CSI in the city of Bonn (67.5 years) as well as that of those who received surgery (68.1 years) were higher than the findings of previous studies, in which the mean age and median were between 54 and 56 years $[6,7,13]$. The higher mean age in the present study may have been due to the more balanced gender ratio, which was 1.03:1 (male: female) for all 130 patients and 1.35:1 (male: female) for those who received surgery. In contrast, studies by Fredo et al. (2012 and 2014) found the percentage of men with CSI to be $68 \%$ and $69 \%$, respectively $[6,7]$, which resulted in a male:female ratio of 2.13-2.23:1 in Norway. However, the gender distribution in the USA in 2018 was 1.5:1 (male:female) [13], which was closer to the ratio found by the present study. Brolin et al. (2002) showed that, despite an average ratio of 2.3:1 (male:female), this ratio had dropped from 3.1:1 in 1987 to 1.7:1 in 1999; therefore, the number of women with CSI increased considerably [2]. Not only did the incidence of CSI increase with increasing age, specifically for women, whose average was higher than that of men $[6,7]$, but the incidence of CSI in women older than 65 years in Sweden was also more than twice as high as the incidence in the general population [2]. Therefore, the greater number of women in the present study may have accounted for the comparatively high mean age.

In the USA, $33.5 \%$ of all CSI are treated with surgery, $17.2 \%$ of which receive an open stabilisation [13]. In Norway, the number of CSI treated with surgeries was stated as $26.6 \%$ [7] and $18 \%$ [6]. Conservative treatment was
Table 2 Incidence of CSI surgeries and concomitant neurologic deficits in the city of Bonn over a 6-year study period

\begin{tabular}{lll}
\hline & Total/year $[n]$ & $\begin{array}{l}\text { Incidence } \\
{[100,000 \text { person }} \\
\text { years }]\end{array}$ \\
\hline Inhabitants & $\begin{array}{l}314,000(\min .309,000 ; \\
\text { max. 320,000) }\end{array}$ \\
CSI surgeries & 10.17 & 3.24 \\
CSI surgeries in the upper cervical spine (C0-C2) & 5.50 & 1.75 \\
CSI surgeries in the subaxial cervical spine (C3-C7) & 4.83 & 1.54 \\
CSI with neurologic deficits & 2 & 0.64 \\
\hline
\end{tabular}


performed in $68.7 \%$ of the CSI, while $4.7 \%$ required no treatment [7]. The annual incidence of CSI surgeries was estimated to be 3.0/100,000 inhabitants [6], which was concordant but slightly lower than the rate of occurrence in Bonn found by the present study (3.24/100,000 person years). In contrast to studies of Scandinavia and North America, the present study could not determine the number of simple injuries necessitating no or conservative treatment that were, therefore, treated on an outpatient basis or in a peripheral hospital without our knowledge. Thus, the incidence for CSI could not be calculated by the present study. It also has to be mentioned that the amount of conservatively treated or not treated CSI only represents the rates of the Level 1 trauma centre itself. On account of these numbers, it is only valid to conclude that the rate of patients being treated non-surgically for CSI is $\geq 53.1 \%$, while the percentage of CSI needing surgery is $\leq 46.9 \%$ being conform with the international average for CSI needing surgery $(18-33.5 \%)[6,7,13]$.

The slightly higher demand for CSI surgeries in the present study as compared to the study in Norway may have been due to a lower threshold for surgery as a treatment for CSI in Germany. An international comparison showed that German spine surgeons chose surgery in $94.2 \%$ of CSI patients and significantly more often $(p<0.05)$ than their colleagues in the Netherlands who decided upon surgery in only $58.1 \%$ [14]. The tendency to perform surgery more often in the present study may have been due to a lower threshold, but it could also have been due to the higher number of elderly and female patients with CSI. Because of a lower bone quality in elderly women and higher risk of insufficient fracture healing, surgery can prevent secondary complications and non-unions. For further clarification of this aspect, additional research is necessary.

Neurologic deficits occurred with an incidence of $0.64 / 100,000$ person years in the present study, and the incidence of complete paraplegia was $0.21 / 100,000$. Since not all CSI in Bonn were captured in this study, the total rate of neurologic deficits in CSI and the rate of CSI without neurologic deficits could not be determined. Based on the included patients and the total number of patients (130) identified in the present study, with 12 of the 130 patients suffering from neurologic deficits, the rate could be assumed to be $<9.2 \%$. In 1996, Hu et al. found a rate of $77 \%$ for CSI without neurologic deficits [8], while Fredo et al. found a rate of $15 \%$ with and 79\% without neurologic deficits in 2012 [7] resulting in an annual incidence of CSI with neurologic deficits of 1.2/100,000 inhabitants. In a further study, Fredo et al. (2014) found neurologic deficits in CSI in only $4.7 \%$ of patients and isolated cervical spinal cord injuries without vertebral injuries in $12.7 \%$ of patients [6]. Furthermore, Passias et al. (2018) found an association between neurologic deficits and injuries in the subaxial cervical spine (upper cervical spine, $5 \%$; subaxial cervical spine, $6.7 \%$, respectively)
[13]. The consideration with a division into the upper and subaxial cervical spine, as well as spinal cord injuries with and without osseo-ligamentous lesions, may explain the low incidence of accompanying neurologic deficits in the present study. With this knowledge, the rates of accompanying neurological deficits stated in previous studies (34-65\%) [2, 11, 16] seem high. Similarly, the amount of complete spinal cord injuries in patients with CSI in the present study $(<3.1 \%)$ was almost as low as that found by Fredo et al. in $2012(2 \%)$ [7] and considerably lower than that found by Leucht et al. in 2009 (19.7\%) [11]. The low incidence of neurologic deficits and complete spinal cord injuries in the present study may have been a result of the greater number of women and of injuries in the upper cervical spine. Injuries of the upper cervical spine occur specifically in elderly women and are usually caused by low-energy trauma [12]. These factors, as well as the increased width of the spinal canal in the upper cervical spine, which better compensates stenoses, reduce the risk for severe neurological damage [5].

Studies in the USA found a mean length of hospital stay of 8.63 days [13] and $9.6 \pm 12$ days [4]. In contrast, a Swedish register study found that $>92 \%$ of patients with CSI and $>96 \%$ of patients with cervical soft tissue injuries had a mean length of hospital stay of $\leq 30$ days [2]. Thus, $>35 \%$ of patients with CSI and $>25 \%$ of patients with soft tissue injuries in the neck had a mean length of hospital stay of 8-30 days, which was similar to that of patients receiving surgery in the present study $(23.0 \pm 20.3$ days). Healthcare systems in central Europe, the USA, and even within Europe differ, possibly resulting in different hospitalisation durations. For instance, the reduced use of halo fixators and preferred use of open surgery in Europe could result in longer hospitalizations than in the USA [6].

This study was the first to calculate the incidence of surgeries as well as neurologic deficits due to CSI in a major German city. The limitations of the study were that only patients with a permanent residence within the city and who were treated in the only available local university hospital were included. Hence, the stated incidence can only be considered an estimation. Patients that only visited the city or worked in the city but had residency outside of the city were not included. Because of overlapping rural catchment areas with neighbouring Level I trauma centres and maximum medical care hospitals, the overall incidence of CSI surgeries in Bonn may have been underestimated. Additionally, injuries that were treated on an outpatient basis or in peripheral hospitals and classified as stable, thereby necessitating no or conservative therapy, could not be detected.

Furthermore, patients who died in the preclinical phase due to trauma and therefore never received hospital treatment could not be detected. Post-mortem studies have shown that $21-24 \%$ of patients who die at the site of the accident have CSI with spinal cord injuries $[1,3]$. In a 
register study, Fredo et al. (2014) estimated that $10 \%$ of CSI were undetected and therefore assumed an actual annual incidence for CSI of $18 / 100,000$ inhabitants in Norway [6]. Due to the different healthcare systems, the amount of undetected CSI in the present study may have been even higher, potentially $30 \%$. The incidence of surgeries for CSI, however, was not affected by undetected CSI. Still, to display the incidence of CSI and their need for surgical treatment, further studies including patients treated in peripheral hospitals and on an outpatient basis are needed.

\section{Conclusion}

Based on calculations in a German city, the annual need for surgeries to treat CSI and the concurrent neurologic deficits were assessed, providing insights into the local supply situation for care research. While both rates showed no significant changes over a six-year study period, the incidence of CSI surgeries as well as the mean age and rate of women was higher in Germany compared to other studies. For long-term demand planning with adaptability to demographic changes, further cross-regional or register studies including long-term follow-up are necessary.

Author contribution Conzeptualization: Koroush Kabir, Jasmin Scorzin; methodology: Roslind Karolina Hackenberg, Paul Stoll, Kristian Welle; formal analysis and investigation: Roslind Karolina Hackenberg, Paul Stoll, Martin Gathen and Charlotte Rommelspacher. Writingoriginal draft preparation: Roslind Karolina Hackenberg, Paul Stoll; writing — review and editing: all authors. Supervision: Koroush Kabir, Jasmin Scorzin, Kristian Welle.

Funding Open Access funding enabled and organized by Projekt DEAL.

Data availability Not applicable.

Code availability Not applicable.

\section{Declarations}

Ethical approval This study was approved by the local ethics committee of the University Hospital Bonn (local review board number 250/18). This study was performed in accordance with the ethical standards of the institutional and national research committee and the 1964 Helsinki declaration and its later amendments.

This article does not contain any studies with animals performed by any of the authors.

Consent to participate Not applicable.

Consent for publication Not applicable.
Presentation at a conference Not applicable.

Conflict of interest The authors declare no competing interests.

Open Access This article is licensed under a Creative Commons Attribution 4.0 International License, which permits use, sharing, adaptation, distribution and reproduction in any medium or format, as long as you give appropriate credit to the original author(s) and the source, provide a link to the Creative Commons licence, and indicate if changes were made. The images or other third party material in this article are included in the article's Creative Commons licence, unless indicated otherwise in a credit line to the material. If material is not included in the article's Creative Commons licence and your intended use is not permitted by statutory regulation or exceeds the permitted use, you will need to obtain permission directly from the copyright holder. To view a copy of this licence, visit http://creativecommons.org/licenses/by/4.0/.

\section{References}

1. Alker GJ, Oh YS, Leslie EV, Lehotay J, Panaro VA, Eschner EG (1975) Postmortem radiology of head neck injuries in fatal traffic accidents. Radiology 114:611-617. https://doi.org/10.1148/ 114.3.611

2. Brolin K, von Holst H (2002) Cervical injuries in Sweden, a national survey of patient data from 1987 to 1999 . Inj Control Saf Promot 9:40-52. https://doi.org/10.1076/icsp.9.1.40.3318

3. Bucholz RW, Burkhead WZ, Graham W, Petty C (1979) Occult cervical spine injuries in fatal traffic accidents. $J$ Trauma 19:768-771. https://doi.org/10.1097/00005373-19791 0000-00009

4. Clayton JL, Harris MB, Weintraub SL, Marr AB, Timmer J, Stuke LE, McSwain NE, Duchesne JC, Hunt JP (2012) Risk factors for cervical spine injury. Injury 43:431-435. https://doi. org/10.1016/j.injury.2011.06.022

5. Dowdell J, Kim J, Overley S, Hecht A (2018) Biomechanics and common mechanisms of injury of the cervical spine. Handb Clin Neurol 158:337-344. https://doi.org/10.1016/B978-0-44463954-7.00031-8

6. Fredo HL, Bakken IJ, Lied B, Ronning P, Helseth E (2014) Incidence of traumatic cervical spine fractures in the Norwegian population: a national registry study. Scand J Trauma Resusc Emerg Med 22:78. https://doi.org/10.1186/s13049-014-0078-7

7. Fredo HL, Rizvi SA, Lied B, Ronning P, Helseth E (2012) The epidemiology of traumatic cervical spine fractures: a prospective population study from Norway. Scand J Trauma Resusc Emerg Med 20:85. https://doi.org/10.1186/1757-7241-20-85

8. Hu R, Mustard CA, Burns C (1996) Epidemiology of incident spinal fracture in a complete population. Spine 21:492-499. https://doi.org/10.1097/00007632-199602150-00016

9. Jackson AB, Dijkers M, Devivo MJ, Poczatek RB (2004) A demographic profile of new traumatic spinal cord injuries: change and stability over 30 years. Arch Phys Med Rehabil 85:1740-1748. https://doi.org/10.1016/j.apmr.2004.04.035

10. Kamravan HR, Haghnegahdar A, Paydar S, Khalife M, Sedighi M, Ghaffarpasand F (2014) Epidemiological and clinical features of cervical column and cord injuries; a 2-year experience from a large trauma center in southern Iran. Bull Emerg Trauma 2:32-37

11. Leucht P, Fischer K, Muhr G, Mueller EJ (2009) Epidemiology of traumatic spine fractures. Injury 40:166-172. https://doi.org/ 10.1016/j.injury.2008.06.040

12. Lomoschitz FM, Blackmore CC, Mirza SK, Mann FA (2002) Cervical spine injuries in patients 65 years old and older: 
epidemiologic analysis regarding the effects of age and injury mechanism on distribution, type, and stability of injuries. AJR Am J Roentgenol 178:573-577. https://doi.org/10.2214/ajr. 178.3.1780573

13. Passias PG, Poorman GW, Segreto FA, Jalai CM, Horn SR, Bortz CA, Vasquez-Montes D, Diebo BG, Vira S, Bono OJ, De La Garza-Ramos R, Moon JY, Wang C, Hirsch BP, Zhou PL, Gerling M, Koller H, Lafage V (2018) Traumatic fractures of the cervical spine: analysis of changes in incidence, cause, concurrent injuries, and complications among 488,262 patients from 2005 to 2013. World Neurosurg 110:e427-e437. https:// doi.org/10.1016/j.wneu.2017.11.011

14. Pishnamaz M, Curfs I, Uhing D, Herren C, van Santbrink H, Mueller CA, Scholz M, Lichte P, Rijkers K, Boselie TF, Hildebrand F, Willems PC, Kobbe P (2019) Two-nation comparison of classification and treatment of subaxial cervical spine fractures: an internet-based multicenter study among spine surgeons. World Neurosurg 123:e125-e132. https://doi.org/10. 1016/j.wneu.2018.11.078

15. Ryan MD, Henderson JJ (1992) The epidemiology of fractures and fracture-dislocations of the cervical spine. Injury 23:38-40. https://doi.org/10.1016/0020-1383(92)90123-a

16. Wang H, Xiang Q, Li C, Zhou Y (2013) Epidemiology of traumatic cervical spinal fractures and risk factors for traumatic cervical spinal cord injury in China. J Spinal Disord Tech 26:E306-313. https://doi.org/10.1097/BSD.0b013e3182886db9

Publisher's note Springer Nature remains neutral with regard to jurisdictional claims in published maps and institutional affiliations. 